University of Nebraska - Lincoln

DigitalCommons@University of Nebraska - Lincoln

Nutrition and Health Sciences -- Faculty

Publications

Nutrition and Health Sciences, Department of

2011

\title{
Correlation of Omega-3 Fatty Acids Intakes with Acculturation and Socioeconomic Status in Midwestern Latinas
}

\author{
Karina R. Lora \\ University of Connecticut, lora@uchc.edu \\ Nancy M. Lewis \\ University of Nebraska--Lincoln, nlewis2@unl.edu \\ Kent M. Eskridge \\ University of Nebraska - Lincoln, keskridge1@unl.edu \\ Kaye Stanek-Krogstrand \\ University of Nebraska-Lincoln, kstanek1@unl.edu \\ Daryl A. Travnicek \\ University of Nebraska-Lincoln
}

Follow this and additional works at: https://digitalcommons.unl.edu/nutritionfacpub

Part of the Dietetics and Clinical Nutrition Commons

Lora, Karina R.; Lewis, Nancy M.; Eskridge, Kent M.; Stanek-Krogstrand, Kaye; and Travnicek, Daryl A., "Correlation of Omega-3 Fatty Acids Intakes with Acculturation and Socioeconomic Status in Midwestern Latinas" (2011). Nutrition and Health Sciences -- Faculty Publications. 5.

https://digitalcommons.unl.edu/nutritionfacpub/5

This Article is brought to you for free and open access by the Nutrition and Health Sciences, Department of at DigitalCommons@University of Nebraska - Lincoln. It has been accepted for inclusion in Nutrition and Health Sciences -- Faculty Publications by an authorized administrator of DigitalCommons@University of Nebraska - Lincoln. 
Published in Journal of Immigrant and Minority Health 13 (2011), pp. 111-118; doi: 10.1007/s10903-009-9314-z

Copyright (C) 2010 Springer Science+Business Media, LLC. Used by permission.

Published online January 23, 2010

\title{
Correlation of Omega-3 Fatty Acids Intakes with Acculturation and Socioeconomic Status in Midwestern Latinas
}

\author{
Karina R. Lora, ${ }^{1}$ Nancy M. Lewis, ${ }^{2}$ Kent M. Eskridge, ${ }^{3}$ \\ Kaye Stanek-Krogstrand, ${ }^{2}$ and Daryl A. Travnicek ${ }^{3}$
}

1. Center for Public Health and Health Policy, University of Connecticut, 2006 Hillside Road Unit 1109, Storrs, CT 06269, USA

2. Department of Nutrition and Health Sciences, University of Nebraska-Lincoln, Lincoln, NE, USA

3. Department of Statistics, University of Nebraska-Lincoln, Lincoln, NE, USA

Corresponding author - Karina R. Lora, email lora@uchc.edu

\begin{abstract}
Background: Low socioeconomic status (SES) and acculturation of Latino immigrants in the U.S. are linked to a decrease in diet quality. Methods: Interviews were conducted with 162 first-generation Latinas to examine the association of SES and acculturation with intake of omega-3 $(n-3)$ fatty acids. Each participant provided dietary intake by use of a validated $n-3$ food frequency questionnaire administered twice, 4 weeks apart, three 24-h recalls, sociodemographic information and completed the 5-item Short Acculturation Scale. Results: Mean intakes of Total $n-3$, a-linolenic acid (ALA), eicosapentaenoic acid (EPA) and docosahexaenoic acid (DHA) (g/d) were 1.2 $\pm 0.7,1.1 \pm 0.6$, and $0.1 \pm 0.1$, respectively. After adjusting for energy intake, education was significantly correlated with EPA + DHA intakes, and acculturation was significantly correlated with Total $n-3$, ALA and EPA + DHA intakes. Foods sources of EPA + DHA eaten by at least $50 \%$ of participants were chicken, shrimp, tuna and eggs. Discussion: Given the beneficial cardiovascular effects of $n-3$ fatty acids, it is important to understand sociocultural factors affecting adequate intake towards an improvement in diet quality in minorities.
\end{abstract}

Keywords: socioeconomic status, acculturation, latinas, omega-3 fatty acids

\section{Introduction}

The omega-3 (n-3) fatty acids (a-linolenic acid (ALA), eicosapentaenoic acid (EPA) and docosahexaenoic acid (DHA) are essential for different physiological processes in humans [1-3]. Epidemiologic and interventional studies have demonstrated the beneficial effects of $n-3$ fatty acids on cardiovascular disease (CVD) [4-6]. However, greater benefits on cardiovascular health have been attributed to EPA and DHA compared to ALA $[1,7,8]$ due to their conversion rate in the body. Food sources of $n-3$ fatty acids are flaxseeds, walnuts, canola oil, and fatty fish $[7,9]$. Adequate Intakes (AI) of ALA for females $\geq 19$ years have been set at $1.1 \mathrm{~g} / \mathrm{d}$ [2], and a combined minimum intake of $0.5 \mathrm{~g} / \mathrm{d}$ EPA and DHA for cardiovascular health has been recommended [10].
In Nebraska, cardiac patients, physically active adults, and low-income pregnant women reported total $n-3$ fatty acid intakes of $0.18-10.15,0.90 \pm 0.12$, and $1.06 \pm 0.03 \mathrm{~g} / \mathrm{d}$, respectively, and a low intake of marine foods, sources of EPA and DHA [11-13]. The National Health and Nutrition Examination Survey (NHANES), 1999-2000 reported intakes (g/d) of 1.3 for ALA, and in the range of 0.03-0.04, and 0.06-0.07 for EPA and DHA, respectively, for U.S. women 2059 years [14]. In comparison, lower intakes $(\mathrm{g} / \mathrm{d})$ of ALA, EPA and DHA in the range of 1.1-1.2, 0.02-0.03, and $0.05-0.06$, respectively are reported for MexicanAmerican women 20-49 years in the U.S. [15]. Most recently What We Eat in America 2005-2006 [16] reported intake $(\mathrm{g} / \mathrm{d})$ in Mexican-American 20 years and older of 1.37 for ALA, 0.05 (with standard error greater 
than $30 \%$ ) for EPA and 0.09 for DHA based on a 24-h food intake period. While national dietary data indicates that population groups in the U.S. meet the AI for ALA, the recommended intakes of EPA and DHA for cardiovascular health are not met. Furthermore, populations in certain geographic areas of the U.S. such as the Midwest may have different intakes in part explained by the low accessibility of food sources, especially marine-food sources, of $n-3$ fatty acids. Hence, average intake from national data need to be interpreted cautiously and not generalized.

Research has linked the socioeconomic status (SES) of individuals to health, and several studies have shown a positive association of SES (income, education, employment) with intake of fruits and vegetables, and nutrients $[17,18]$ and a negative association with chronic diseases [19]. For instance, income and educational attainment are recognized underlying factors that affect the rate of heart diseases in minorities and low-income populations [20]. Minority women are more likely to be in poorer health, suffer from premature death, disease, disabilities and face socioeconomic and cultural barriers that increase their chances for health disparities compared to Caucasian women [21]. It has been reported that Latinas have lower awareness of heart disease as their leading cause of death compared to Caucasian women [22], and that Mexican-American women have a prevalence for CVD of 34\% [23].

Research has established that in minority/ethnic groups CVD risk factors are influenced by behavioral, cultural and societal factors [24, 25]. One of these factors is the social and cultural mechanism acculturation. Acculturation is defined as "the process by which immigrants adopt the attitudes, values, customs, beliefs, and behaviors of a new culture" [26]. Research on the association of acculturation with diet quality of Latino immigrants in the U.S. has been mixed. Greater acculturation of Latinos to the U.S. nutritional habits has been associated with less health-related dietary behaviors [27, 28], while other studies found that poorer dietary habits are associated with less acculturation [29]. However, given the beneficial cardiovascular effects of the $n-3$ fatty acids, few studies have reported intakes in this cultural group and no study has used a dietary instrument culturally relevant to the Latino population or examined the association of $n-3$ intake with acculturation and SES of Latino immigrants in the U.S. This association becomes relevant as heart diseases are the leading cause of mortality among Latino accounting for $24 \%$ of the deaths of Latinos living in this country [30]. Therefore, the objective of the present study was to examine the association of age, SES (education, income, employment) and acculturation on intake of $n-3$ fatty acids in U.S Midwestern Latinas.

\section{Methods}

\section{Participants and Study Settings}

The study population consisted of 162 apparently healthy first-generation Midwestern Latinas from the cities of Lincoln and Omaha in Nebraska, who were between the ages of 20-50 years. These women were not pregnant or lactating at the time of the study and did not report having current illness(s) or smoking. Participants were recruited from Latino community centers, churches, and physical activity community service project sites. Community health workers and social workers served as liaisons with project staff. Convenience and snowball sampling were employed to facilitate recruitment. Snowball sampling involves collecting data on some members of the target population that can be located. These members are asked to provide information to locate other members of the same population that share similar characteristics. It is a non-probabilistic type of sampling useful when sampling members of a special population that are difficult to locate [31].

Only one participant was recruited from each household or family. One-on-one interviews in Spanish were conducted with each participant between October 2007 and August 2008 by a trained bicultural interviewer at the participant's home or recruitment site. Each participant met with the interviewer twice, 4 weeks apart and completed two food frequency questionnaires (FFQ) to estimate $n-3$ fatty acids dietary intake, and provided three non-consecutive 24-h recalls in the same time period [32]. Sociodemographic and acculturation information was collected during the first interview. A questionnaire adapted from the Behavioral Risk Factor Surveillance System 2006 Questionnaire, Spanish version [33], was used to obtain sociodemographic information. The same interviewer conducted all interviews in an attempt to minimize variation in assessment protocol and maintain quality control across all subjects. Participants who completed the study received a $\$ 30$ gift card as compensation for their participation. The study was approved by the Institutions Review Board for the Protection of Human Subjects.

\section{Assessment of Omega-3 Fatty Acid and Energy Intakes}

The $n-3$ fatty acid intakes of participants were assessed as part of a validation study of a culturally appropriate $n-3 F F Q$ developed for Midwestern Latinas [32]. Briefly, the $n-3 F F Q$ contained 209 items (including 15 culturally-specific dishes) and was developed to estimate Total $n-3$ fatty acid, ALA, EPA, and DHA intakes. Foods included in the FFQ provided $\geq 10 \mathrm{mg}$ Total $n-3$ fatty acid/medium serving. Frequency of consumption was classified as none, once a month, 
two to three times a month, one to two times a week, three to four times a week, five to six times a week, and daily (once or twice a day). Estimated intakes of Total $n-3$, ALA, EPA and DHA on the $n-3$ FFQ were calculated for each food by multiplying the frequency of consumption by the amount eaten of that food for the respective $n-3$ fatty acid content of that food. The FFQ was designed to estimate $n-3$ fatty acid intake in 1 month period (4 weeks). Energy intake was obtained from the three non-consecutive 24-h recalls, utilized as the reference method, provided by each participant in the 4 week period. Food models, kitchen measuring utensils, and pictures were used to illustrate portions sizes for both dietary intake assessments. For the purpose of this study, EPA plus DHA intakes were grouped due to their combined reported role in cardiovascular health. In addition, we assessed total fat, and saturated fat intakes from the 24-h recalls to provide information of participants' diet quality given that high intake of these macronutrient may increase the risk for heart diseases. Dietary intakes were analyzed using the Nutrition Data System for Research software version NDSR 2007 developed by the Nutrition Coordinating Center (NCC), University of Minnesota, Minneapolis, $\mathrm{MN}$ [34].

\section{Acculturation Measurement}

The 5-item version of the Short Acculturation Scale for Hispanics (SASH) developed by Marin et al. [35] was used to assign participants as low or high levels of acculturation. Reported a correlation is 0.90 for the 5-item scale. The SASH consists of five questions: (1) In general, what language do you read and speak? (2) What was the language(s) you used as a child? (3) What language(s) do you usually speak at home? (4) In which language(s) do you usually think? and (5) What language(s) do you usually speak with your friends? Each question in the acculturation scale is scored on a 5-point Likert scale ranging from "Only Spanish" (1) to "Only English" (5) to assess acculturation based on language spoken [35]. Responses were each scored on a scale from 1 to 5 . An acculturation score was calculated by assigning the mean acculturation score of each participant. The acculturation scale allocated Latinas as low or high acculturation based on a dichotomous variable. A $<2.5$ score indicated low acculturation and $\geq 2.5$ score indicated high acculturation.

\section{Statistical Analysis}

Key verification was used as quality control for data entry. Descriptive statistics and Spearman correlation were used for statistical analysis. Age, education, household income, employment and acculturation were set as ordi- nal demographic variables. Age had three levels: 20-30, 31-40, and 41-50 years. Education had four levels: never went to school, completed high school, 1-3 years of college, college graduate. Household income had eight range levels: from less than $\$ 10,000-\$ 75,000$ or more. Employment had three levels: employed full time, employed part time, not employed outside the home; and acculturation score. The $n-3 F F Q$ produced dietary data on Total $n-3$, ALA and EPA and DHA. EPA and DHA intake values were added and used as the variable EPA + DHA. A mean energy intake was obtained from the administration of the three 24-h recalls and used to adjust Total $n-3$, ALA and EPA + DHA for energy to control for confounding [36]. Medians intake of adjusted Total $n-3$, ALA, EPA + DHA was calculated from the first and second administration of the FFQ, and used as intake variables. Spearman's correlations $\left(r_{\mathrm{s}}\right)$ were calculated to estimate the correlation among the demographic and intake variables. All statistical analyses were performed with SAS (version 9.1 TS level 1M3 2006, SAS Institute, Inc., Cary, NC).

\section{Results}

Table 1 reports detailed demographic characteristic of Latinas participating in the study. The mean age was $34.3 \pm 8.2$ years. Over two-thirds of female participants were born in Mexico; other participant origin included Central and South America, Dominican Republic, and Puerto Rico. Participants had a mean age of first arriving in the U.S. of $25.1 \pm 9.0$ years, and mean years of permanency in the U.S. of $9.3 \pm 6.4$ years. Spanish was the dominant language spoken at home $(80 \%), 74 \%$ of women were married or had a live-in partner, and 54\% had an average of two children living at home.

Although the average energy intake of participants was $1,498 \mathrm{kcal} / \mathrm{d}$ and had a total fat and saturated fat intake (\% of energy) of 31 and $10 \%$, respectively, sixty percent of participants had at least 1 day in which their total fat intake was $\geq 35 \%$ of calories, and $76 \%$ of participants had at least 1 day in which their saturated fat intake was $\geq 10 \%$ of calories. Mean daily intakes $( \pm S D)$ of Latinas assessed by the mean of the first and second administration of the FFQs $(\mathrm{g} / \mathrm{d})$ were $1.21 \pm 0.70$ [range $0.29-5.11$ ] for Total $n-3,1.10 \pm 0.65$ [range $0.27-4.62$ ] for ALA, and $0.12 \pm 0.10$ [range 0.004-0.61] for EPA + DHA. Median intake for Total $n-3$ was $1.06 \mathrm{~g} / \mathrm{d}$, for ALA $0.98 \mathrm{~g} / \mathrm{d}$ and for EPA + DHA $0.10 \mathrm{~g} / \mathrm{d}$. After adjusting for energy intake, EPA + DHA intake was positively correlated with education $\left(r_{\mathrm{s}}=0.20\right)$ and acculturation was positively correlated with Total $n-3$ $\left(r_{\mathrm{s}}=0.23\right)$, ALA $\left(r_{\mathrm{s}}=0.22\right)$, and EPA + DHA $\left(r_{\mathrm{s}}=0.19\right)$. Age was not significantly correlated with intake of $n-3$ fatty acids. Spearman correlations of Total $n-3$, ALA, 
EPA + DHA with demographics are shown in Table 2. Table 3 reports the rank order listing of foods sources of EPA + DHA consumed by study participants. Chicken, shrimp, tuna and eggs were sources of EPA + DHA

Table 1. Sociodemographic and acculturation characteristics of Latinas $(n=162)$

\begin{tabular}{|c|c|}
\hline Age $^{a}$ & $34.3 \pm 8.2$ \\
\hline \multicolumn{2}{|l|}{ Age range $(\%)$} \\
\hline $20-30$ years & 39.5 \\
\hline $31-40$ years & 35.2 \\
\hline $41-50$ years & 25.3 \\
\hline Education (years) $^{\mathrm{a}}$ & $10.7 \pm 4.1$ \\
\hline Never went to school (\%) & 1.2 \\
\hline High school graduate (\%) & 61.1 \\
\hline $1-3$ years college $(\%)$ & 17.3 \\
\hline College graduate (\%) & 20.4 \\
\hline \multicolumn{2}{|l|}{ Annual household income (\%) } \\
\hline$<\$ 10,000$ & 11.8 \\
\hline$\$ 10,000-\$ 20,000$ & 42.6 \\
\hline$\$ 21,000-\$ 35,000$ & 31.5 \\
\hline$\$ 36,000-\$ 50,000$ & 10.5 \\
\hline$>\$ 50,000$ & 3.1 \\
\hline \multicolumn{2}{|l|}{ Language spoken at home (\%) } \\
\hline English & 8 \\
\hline Spanish & 80.2 \\
\hline Spanish and English & 11.7 \\
\hline \multicolumn{2}{|l|}{ Employment (\%) } \\
\hline Full-time employed & 32.7 \\
\hline Part-time employed & 19.8 \\
\hline Unemployed/full-time homemaker & 47.5 \\
\hline \multicolumn{2}{|l|}{ Acculturation distribution (\%) } \\
\hline Low acculturation & 86 \\
\hline High acculturation & 14 \\
\hline Age when first came to the US (years) ${ }^{\mathrm{a}}$ & $25.1 \pm 9.0$ \\
\hline Years of permanency in the US (years) ${ }^{a}$ & $9.3 \pm 6.4$ \\
\hline
\end{tabular}

a. Mean \pm SD

Table 2. Spearman correlations ${ }^{\mathrm{a}}$ between Total $n-3^{\mathrm{b}}, \mathrm{ALA}^{\mathrm{c}}$, and $\mathrm{EPA}^{\mathrm{d}}+\mathrm{DHA}^{\mathrm{e}}$, and age, education, income, employment and acculturation in Latinas $(n=162)$

\begin{tabular}{lccc}
\hline & Total $n-3$ & ALA & EPA + DHA \\
\hline Age & -0.060 & -0.100 & 0.132 \\
Education & 0.078 & 0.067 & $0.204^{*}$ \\
Income & -0.044 & -0.062 & 0.106 \\
Employment & 0.006 & 0.028 & 0.032 \\
Acculturation & $0.229^{*}$ & $0.223^{*}$ & $0.193^{*}$ \\
\hline
\end{tabular}

* $P<0.05$

a. Adjusted per energy intake

b. Total $n-3=$ Total omega-3

c. ALA a-linolenic acid

d. EPA Eicosopentaenoic acid

e. DHA Docosohexaenoic acid eaten by $50 \%$ or more of participants in the present study. Although the $n-3$ FFQ included culturally-specific dishes in attempt to capture a wide inclusion of foods sources of $n-3$ fatty acids in the study population, only one ethnic dish, "Mole," made the rank list of foods sources of EPA + DHA.

\section{Discussion}

Latinas met the AI for ALA for their age group $(1.10 \mathrm{~g} / \mathrm{d})$; however, this finding needs to be interpreted cautiously. The median intake for ALA was $0.98 \mathrm{~g} / \mathrm{d}$ with intakes that ranged from 0.27 to $4.62 \mathrm{~g} / \mathrm{d}$ for the participants. Although mean energy intake was $1,498 \mathrm{kcal} / \mathrm{d}$, energy intakes ranged from 246 to $4,145 \mathrm{kcal} / \mathrm{d}$. Thus, the wide range in ALA consumption could be in part explained by the extreme self reported energy intake values of a few participants, which influenced their $n-3$ fatty acid intakes and consequently ALA intakes. EPA + DHA intake of Latinas was $0.12 \pm 0.10 \mathrm{~g} / \mathrm{d}$. ALA intake of women in the present study was lower than reported intakes of U.S. women 20-49 years (range 1.2-1.3 g/d) [15], and for women 2059 years from NHANES 1999-2000 data (1.3 g/d) [14]. Similarly, What We Eat in America 2005-2006 [16] reported ALA intakes (range 1.34-1.47 g/d) for women

Table 3. Rank order listing of foods sources of $\mathrm{EPA}^{\mathrm{a}}+\mathrm{DHA}^{\mathrm{b}}$ in the study population ${ }^{\mathrm{C}}(n=162)$

\begin{tabular}{llc}
\hline $\begin{array}{l}\text { Rank } \\
\text { order }\end{array}$ & Food & $\begin{array}{c}\text { \% Participants who } \\
\text { ate the food }\end{array}$ \\
\hline 1 & Chicken breast, no skin & 78 \\
2 & Shrimp & 77 \\
3 & Chicken leg, no skin & 74 \\
4 & Tuna canned in water & 61 \\
5 & Egg boiled & 56 \\
6 & Tilapia & 49 \\
7 & Mole & 35 \\
8 & Turkey & 33 \\
9 & Chicken burger, breaded & 30 \\
10 & Fresh or frozen salmon & 30 \\
11 & Turkey hot dogs & 27 \\
12 & Chicken burger, grilled & 27 \\
13 & Chicken nuggets & 27 \\
14 & Fish fillets, breaded & 24 \\
15 & Chicken leg with skin & 23 \\
16 & Tuna canned in oil & 19 \\
17 & Chicken breast with skin & 12 \\
18 & Sardines canned in oil & 10 \\
\hline
\end{tabular}

a. EPA Eicosopentaenoic acid

b. DHA Docosohexaenoic acid

c. Intake assessed by the mean of two FFQs

d. Typical Mexican dish made up of chicken 
20-49 years to be higher than intakes of Latino women in the present study. Reported EPA and DHA intakes are 0.05 and $0.09 \mathrm{~g} / \mathrm{d}$, respectively.

Higher ALA intakes are reported for 20-49 year old White non-Hispanic women $(1.3 \mathrm{~g} / \mathrm{d})$ and Black nonHispanic females (range: 1.1-1.4 g/d) compared to our results [15]. What We Eat in America 2005-2006 [16] reported higher ALA intakes for non-Hispanic Whites $(1.59 \mathrm{~g} / \mathrm{d})$, non-Hispanic Blacks $(1.43 \mathrm{~g} / \mathrm{d})$ and Mexican-Americans $(1.37 \mathrm{~g} / \mathrm{d}) 20$ years and older than Latinas in the present study. What We Eat in America 20052006 reported that non-Hispanic Whites had EPA and DHA intakes similar to Latinas $(0.12 \mathrm{~g} / \mathrm{d})$ in the present study but higher intakes are reported for non-Hispanic Blacks $(0.16 \mathrm{~g} / \mathrm{d})$ and Mexican-Americans $(0.14 \mathrm{~g} / \mathrm{d})$. Differences on intake between national data and the preset study could be explained by the type of dietary assessment method used and day(s) that the method was replicated. In the present study we utilized a culturally appropriate $n-3 \mathrm{FFQ}$ that estimated usual intake by assessing it over a long period of time. In contrast, $n-3$ fatty acid intake reported in What We Eat in America 2005-2006 used NHANES data in which dietary information was estimated by intake provided by respondents in 1 day period.

In the present study Latinas met only $20 \%$ of the recommended EPA + DHA intake for cardiovascular health and their consumption was affected by SES and acculturation. Education, an often used indicator of SES in dietary research [37], and linked as risk factor for cardiovascular disease in White [38] and Mexican American women [23] was positively correlated with intake of EPA + DHA. Education has been suggested as the most stable indicator of SES as it captures learning acquired early in life which does not change [39], but may advance over a lifetime. The association of education with $n-3$ fatty acid intakes could be a reflection that Latinas with higher education were able to access and understand the health benefits and food sources of $n-3$ fatty acids especially EPA + DHA which in turn may have affected intake. It has been suggested that the relation between an individual's acquired education and knowledge and diet can influence his or her lifestyle by increasing the person's ability to access and interpret health information, thus generating beneficial health-related behaviors along the course of life [40]. Similarly, other studies have linked higher education to a higher consumption of fish [41, 42], in different populations. Hence, individuals with lower SES compared to those with higher SES are more likely to have poorer diet quality [43]. Fitzgerald et al. [44] reported an association of low SES with less frequency of fish consumption in Puerto Rican women. Similarly, low intakes of EPA and DHA as reported in the frequency of fish consumption of $0.3 \pm 0.2$ times/day were found in Puerto Rican fe- males living in poverty in Connecticut [45]. Other studies have shown a positive association of education with intake of healthful foods such as fruits across ethnic and racial groups [46], and fruits and vegetables servings in non-Hispanic White women [47] and in Whites and Mexican Americans [17].

Although higher acculturation has been linked to negative health-related behaviors such as higher fat intake and low intake of fiber, and fruits and vegetables of Latinos residing in the U.S. [27, 48], other studies have found the opposite [29], thus a conclusive association has yet to be elucidated. Neushouser et al. [27] found that highly acculturated Mexican-Americans had slighter higher, but not statistically significant, scores of fat intake compared to their low acculturated counterparts. Gregory-Mercado et al. [49] reported no significant association between acculturation and total fat intake in a sample of Mexican American women. In contrast, a positive association between acculturation and intake of dietary fat was reported in a national sample of youth [50]. The present study found that higher acculturation was correlated with higher intake of Total $n-3$, ALA and EPA + DHA. We explain that the positive correlation with acculturation in the present study is related to the adoption of dietary practices of the host country [28]. For instance, examples of food sources of ALA are flax seeds, walnuts, canola oil, and green leafy vegetables, and main sources of EPA and DHA are salmon or other fatty fish. These foods may have been consumed more frequently by Latinas with higher "dietary acculturation" [28]. By contrast, the same foods may have been less culturally relevant to low acculturation Latinas ( $85 \%$ of the sample) and to Latinas with less understanding and awareness of the health benefits of $n-3$ fatty acids, as educational attainment was correlated with intake of EPA + DHA. Nevertheless, several studies have focused on the relationship between dietary intake and acculturation in Latinos, but not specifically on $n-3$ fatty acid intakes, thus we could not draw a conclusion on how the findings of the present study differ from others on intake of the nutrients analyzed. An interesting observation is that the majority of participants in the present study lived in low-income Spanish neighborhoods close to ethnic shops where fresh fish was not commonly sold or was expensive. This observation, along with the findings that majority of Latinas scored as low acculturation and had an average of 9.3 years of permanency in the U.S., could explain the low acculturation of the majority of participants. Immigrants who situate in ethnic enclaves may acculturate slower [51], and this characteristic could have contributed to lower consumption of fresh fish in favor of canned fish as our results show.

Chicken, shrimp, tuna canned in water, boiled eggs and tilapia were foods sources of EPA + DHA eaten by 
most of Latinas ( $50 \%$ or more). In agreement with our findings, the Continuing Survey of Food Intakes by Individuals 1994-1996 reported that meat, poultry and fish contributed to most of the intake of EPA and DHA in women 20 years of age and older [52]. Chicken, followed by shrimp, was the first and most often consumed food source of EPA + DHA of Latinas in the present study. Data from NHANES 1999-2000 [53] showed that most consumed fish is tuna (22\% of fish consumption), with shrimp (16\%) and salmon (9\%) making the list of marine food consumed in the U.S. In contrast to NHANES results, marine food source from where participants in the present study obtained their intake of $\mathrm{EPA}+\mathrm{DHA}$ were shrimp (77\%), tuna $(61 \%)$, tilapia $(49 \%)$ and salmon $(30 \%)$. These differences in sources of intake could have been affected by sociocultural factors that influenced intake in the population studied. Shrimp is commonly eaten in Mexico [54] and was consumed by more than three-fourths of participants. Although crustaceous are considered a medium to low source of EPA and DHA; shrimp was a cultural-ethnic food source from which participants obtained their intake of EPA and DHA. Thus, marine foods intake of these women were likely to resemble their traditional food habits.

Sixty and seventy percent of participants reported to have at least 1 day in which their intakes were greater than the recommended intake (\% of calories) for total (between 25 and $35 \%$ ) and saturated fat $(<10 \%)$, respectively, [55]. A high intake of fat generally increases saturated fat intake, which in turn increases unhealthy blood lipid concentrations, thus augmenting the risk for CVD [55]. Therefore, a healthy diet is a major factor that contributes in reducing heart disease risk. Although we did not assess other CVD related risk factors, the total fat and saturated fat intakes and less than recommended intake of EPA + DHA observed in the present study may make these Latinas vulnerable for heart disease related risk.

Although shrimp and tuna were the most consumed marine foods, their frequency and the amount of intake paired with their lower content of EPA + DHA may have accounted for the low mean intake of $0.12 \mathrm{~g} / \mathrm{d}$ of $\mathrm{EPA}+\mathrm{DHA}$ in the present study. In addition, low accessibility to fresh fish choices in Midwest, education that affected purchase of greater EPA + DHA food sources, and low dietary acculturation of the majority of participants prevented their adoption of eating patterns of the host country and may help explain lower intakes of EPA + DHA found in this study. Nevertheless, taking into account that socioeconomically disadvantaged groups are at higher risk for heart diseases, and the evidence that Latino immigrants increase their risk factors for CVD with length of residency and acculturation to the U.S. [54,56] there is a need to increase promotion of food sources of $n-3$ fatty acids among Latino audiences and especially in low SES Latinos. It is of para- mount importance to support nutrition knowledge as a route to raise awareness of the healthy benefits of $n-3$ fatty acids and encourage recommended amount and frequency of intake of foods such as tuna, sardines and canned salmon which are available at relatively low cost as a strategy to increase diet quality in minorities. It is important to encourage and educate immigrants on the adoption of healthy dietary behaviors of the host country while supporting maintenance of the healthy dietary practices of their country of origin. The study had limitations. The sample population included women from different Latino American regions who had different diet compositions and means of food preparation. We did not control for country of origin and that may have had an effect on the association of dietary intake with the socioeconomic factors measured. In addition, our results represent a regional sample of Midwestern Latinas, thus findings can not be generalized.

In conclusion, educational attainment and acculturation were correlated with intake of $n-3$ fatty acids in Midwestern Latinas. Of particular importance is the EPA + DHA intake of participants, although it increased with education and acculturation, it did not meet the recommended intake for cardiovascular health. The present study makes a contribution in examining for the first time the relationship of acculturation with intakes of $n-3$ fatty acids of Latinas in a geographical area of the U.S. where there is a need to increase our understanding of the social determinants of Latino health. Given the recognized link of low SES to CVD risk factors in minorities, and the beneficial effects of $n-3$ fatty acid intakes on cardiovascular health, this study provides insight on some social determinants of adequate intake of this nutrient in Latinas in the U.S. Midwest.

Acknowledgments - Funding for this study was provided by the Vice-Chancellor for Research Minority Grants at The University of Nebraska. Special thanks to Diana Garcia, Blanca Follwer, Gabriela Ortiz and July Braunsroth for their assistance during recruitment.

\section{References}

1. Arterburn LM, Hall EB, Oken H. Distribution, interconversion, and dose response of $n-3$ fatty acids in humans. Am J Clin Nutr. 2006; 83:1467S-76S.

2. Institute of Medicine. Dietary reference intakes for energy, carbohydrate, fiber, fat, fatty acids, cholesterol, protein, and amino acids. Washington: National Academy Press, 2005.

3. Lee KW, Lip GY. The role of omega-3 fatty acids in the secondary prevention of cardiovascular disease. QJM. 2003; 96:465-80.

4. Jarvinen $\mathrm{R}$, Knekt $\mathrm{P}$, Rissanen $\mathrm{H}$, Reunanen A. Intake of fish and long-chain $n-3$ fatty acids and the risk of coro- 
nary heart mortality in men and women. Br J Nutr. 2006; 95:824-9.

5. He K, Liu K, Daviglus ML, Mayer-Davis E, Jenny NS, Jiang $\mathrm{R}$, et al. Intakes of long-chain $n-3$ polyunsaturated fatty acids and fish in relation to measurements of subclinical atherosclerosis. Am J Clin Nutr. 2008; 88:1111-8.

6. Nilsen DW, Albrektsen G, Landmark K, Moen S, Aarsland $\mathrm{T}$, Woie L. Effects of a high-dose concentrate of $n-3$ fatty acids or corn oil introduced early after an acute myocardial infarction on serum triacylglycerol and HDL cholesterol. Am J Clin Nutr. 2001; 74:50-6.

7. Gebauer SK, Psota TL, Harris WS, Kris-Etherton PM. N - 3 fatty acid dietary recommendations and food sources to achieve essentiality and cardiovascular benefits. Am J Clin Nutr. 2006; 83:1526S-35S.

8. Breslow JL. $N-3$ fatty acids and cardiovascular disease. Am J Clin Nutr. 2006; 83:1477S-82S.

9. Williams CM, Burdge G. Long-chain $n-3$ PUFA: Plant v. marine sources. Proc Nutr Soc. 2006; 65(1):42-50.

10.ISSFAL. Recommendations for intake of polyunsaturated fatty acids in healthy adults. 2008. http://www.issfal.org.uk/index.php?option $=$ com_content\&task $=$ view $\&$ id $=23 \&$ Itemid=8; accessed October 12, 2008.

11. Ritter-Gooder PK, Lewis NM, Heidal KB, Eskridge KM. Validity and reliability of a quantitative food frequency questionnaire measuring $n-3$ fatty acid intakes in cardiac patients in the Midwest: a validation pilot study. J Am Dietetic Assoc. 2006; 106:1251-5.

12.Sindelar C, Scheerger S, Plugge S, Eskridge K, Wander RC, Lewis NM. Serum lipids of physically active adults consuming omega-3 fatty acid-enriched eggs or conventional eggs. Nutr Res. 2004; 24:731-9.

13. Lewis NM, Widga AC, Buck JS, Frederick AM. Survey of omega-3 fatty acids in diets of Midwestern low-income pregnant women. J Agromedicine. 1995; 2:49-57.

14.Ervin RB, Wright JD, Wang CY, Kennedy-Stephenson J. Dietary intake of fats and fatty acids for the United States population: 1999-2000. Adv Data. 2004; 348:1-6.

15.Centers for Disease Control. National Center for Health Statistics. Publication and information product series 11 No. 245. 2008. http://www.cdc.gov/nchs/products/series. htm\#sr11; accessed October 1, 2008.

16. What We Eat in America. National Health and Nutrition Examination Survey (NHANES) 2005-2006. United States Department of Agriculture, Agricultural Research Service. 2009. http://www.ars.usda.gov/Services/docs. htm?docid=17041; accessed October 1, 2009.

17. Dubowitz T, Heron M, Bird CE, Lurie N, Finch BK, Basurto-Dávila R, et al. Neighborhood socioeconomic status and fruit and vegetable intake among whites, blacks, and Mexican Americans in the United States. Am J Clin Nutr. 2008; 87:1883-91.

18. Block G, Rosenberger WF, Patterson BH. Calories, fat and cholesterol: intake patterns in the US population by race, sex and age. Am J Public Health. 1988; 78:1150-5.

19. Gold R, Michael YL, Whitlock EP, Hubbell FA, Mason ED, Rodriguez BL, et al. Race/ethnicity, socioeconomic status, and lifetime morbidity burden in the women's health ini- tiative: a cross-sectional analysis. J Womens Health. 2006; 15:1161-73.

20.Center for Disease Control and Prevention. Office of Minority Health and Health Disparities. 2008. http://www.cdc. gov/omhd/Populations/HL/HL.htm\#Statistics ; accessed November 8, 2008.

21.US Department of Health and Human Services. The Office of Women's Health. 2008. http://www.4woman.gov/owh/; accessed November 8, 2008.

22. Mosca L, Banka CL, Benjamin EJ, Berra K, Bushnell C, Dolor RJ, et al. Evidence-based guidelines for cardiovascular disease prevention in women: 2007 update. Circulation. 2007; 115:1481-501.

23. Rosamond W, Flegal K, Friday G, Furie K, Go A, Greenlund $K$, et al. Heart disease and stroke statistics -2007 update: a report from the American Heart Association Statistics Committee and Stroke Statistics Subcommittee. Circulation. 2007; 115:69-171.

24. Winkleby MA, Kraemer HC, Ahn DK, Varady AN. Ethnic and socioeconomic differences in cardiovascular disease risk factors: findings for women from the Third National Health and Nutrition Examination Survey, 1988-1994. JAMA. 1998; 280:356-62.

25. Anderson NB. Behavioral and sociocultural perspectives on ethnicity and health: introduction to the special issue. Health Psychol. 1995; 14:589-91.

26. Abraido-Laiza AF, White K, Vasquez E. Immigrant populations and health. In: Anderson N, editor. Encyclopedia of health and behavior. Newbury Park: Sage; 2004. p. 533-7.

27. Neuhouser ML, Thompson B, Coronado GD, Solomon CC. Higher fat intake and lower fruit and vegetables intakes are associated with greater acculturation among Mexicans living in Washington State. J Am Diet Assoc. 2004; 104:51-7.

28.Satia-Abouta J, Patterson RE, Neuhouser ML, Elder J. Dietary acculturation: applications to nutrition research and dietetics. J Am Diet Assoc. 2002; 102:1105-18.

29. DiSogra L, Abrams B, Hudes M. Low prevalence of healthful dietary behaviors in a California agricultural county: emphasis on white and Mexican-American adults. J Am Diet Assoc. 1994; 94:544-6.

30. Centers for Disease Control and Prevention. Morbidity and mortality weekly report: Health disparities experiences by Hispanics-United States. 2008. http://www.cdc.gov/mmwr/ $\mathrm{PDF} / \mathrm{wk} / \mathrm{mm}$ 5340.pdf; accessed November 11, 2008.

31. Babbie E. The practice of social research. 12th ed. California: Wadsworth Publishing; 2009.

32. Lora K. Assessment of omega-3 fatty acid intakes and their association with socioeconomic status and acculturation in midwestern Latinas. Doctoral Dissertation. University of Nebraska. 2008.

33. Center for Disease Control and Prevention. National Center for Chronic Disease Prevention and Health Promotion. Behavioral risk factor surveillance system. Questionnaires Spanish version. 2008. http://www.cdc.gov/brfss/questionnaires/ en_espanol.htm; accessed October 1, 2008.

34. Nutrition Coordinating Center (NCC). University of Minnesota, Minneapolis, MN Nutrition Data System for Research software version NDSR 2007. 
35.Marin G, Sabogal F, Vanoss Marin B, Otero-Sabogal R, Perez-Stable EJ. Development of a short acculturation scale for Hispanics. Hisp J Behav Sci. 1987; 9:183-205.

36. Willett WC, Howe GR, Kushi LH. Adjustment for total energy intake in epidemiologic studies. Am J Clin Nutr. 1997; 65:1220S-8S.

37.Fitzgerald N, Damio G, Segura-Pérez S, Pérez-Escamilla R. Nutrition knowledge, food label use, and food intake patterns among Latinas with and without type 2 diabetes. J Am Diet Assoc. 2008; 108:960-7.

38. Winkleby MA, Jatulis DE, Frank E, Fortmann SP. Socioeconomic status and health: how education, income and occupation contribute to risk factors for cardiovascular disease. Am J Public Health. 1992; 826:816-20.

39. Berkman LF, Macintyre S. The measurement of social class in health studies: old measures and new formulations. IARC Sci Publ. 1997; 138:51-64.

40.Galobardes B, Morabia A, Bernstein M. Diet and socioeconomic position: does the use of different indicators matter? Int J Epidemiol. 2001; 30:334-40.

41. Moreira PA, Padrão PD. Educational and economic determinants of food intake in Portuguese adults: a cross-sectional survey. BMC Public Health. 2004; 2:4-58.

42.Xie B, Gilliland FD, Li YF, Rockett HR. Effects of ethnicity, family income and education on dietary intake among adolescents. Prev Med. 2003; 36:30-40.

43. Inglis V, Ball $\mathrm{K}$, Crawford D. Socioeconomic variations in women's diets: what is the role of perceptions of the local food environment? J Epidemiol Commun Health. 2008; 62:191-7.

44. Fitzgerald N, Himmelgreen D, Damio G, Segura-Pérez S, Peng YK, Pérez-Escamilla R. Acculturation, socioeconomic status, obesity and lifestyle factors among low-income Puerto Rican women in Connecticut, U.S., 1998-1999. Rev Panam Salud Publica. 2006; 19:306-13.

45.Himmelgreen DA, Perez-Escamilla R, Segura-Millan S, Romero-Daza N, Tanasescu M, Singer M. A comparison of the nutritional status and food security of drug-using and non-drug-using Hispanic women in Hartford, Connecticut. Am J Phys Anthropol. 1998; 107:351-61.

46.Shea S, Melnik TA, Stein AD, Zansky SM, Maylahn C, Basch CE. Age, sex, educational attainment, and race/ethnicity in relation to consumption of specific foods contributing to the atherogenic potential of diet. Prev Med. 1993; 22:203-18.
47.Gregory-Mercado KY, Staten LK, Ranger-Moore J, Thomson CA, Will JC, Ford ES, et al. Fruit and vegetable consumption of older Mexican-American women is associated with their acculturation level. Ethn Dis. 2006; 16:89-95.

48. Mainous AG 3rd, Diaz VA, Geesey ME. Acculturation and healthy lifestyle among Latinos with diabetes. Ann Fam Med. 2008; 6:131-7.

49. Gregory-Mercado KY, Staten LK, Gillespie C, RangerMoore J, Thomson CA, Giuliano AR, et al. Ethnicity and nutrient intake among Arizona WISEWOMAN participants. J Womens Health. 2007; 16:379-89.

50. Mazur RE, Marquis GS, Jensen HH. Diet and food insufficiency among Hispanic youths: acculturation and socioeconomic factors in the third National Health and Nutrition Examination Survey. Am J Clin Nutr. 2003; 78:1120-7.

51.Pérez-Escamilla R, Putnik P. The role of acculturation in nutrition, lifestyle, and incidence of type 2 diabetes among Latinos. J Nutr. 2007; 137:860-70.

52. Food Surveys Research Group U. Intakes of 19 individual fatty acids: Results from the 1994-1996 continuing survey of food intakes by individuals. Beltsville, MD: USDA, 2005. http://www.ars.usda.gov; accessed June 2, 2009.

53. US Department of Agriculture, US Department of Health and Human Services. Dietary guidelines Advisory Committee report 2005. 2009. http://www.health.gov/dietaryguidelines/dga2005/report/; accessed June 2, 2009.

54. Kittler PM, Sucher KP. Food and culture. 5th ed. Belmont: Thomson Wadsworth; 2008.

55.US Department of Health and Human Services. Dietary guidelines for Americans, 2005. 2009. http://www.health. gov/DietaryGuidelines/dga2005/document/default.htm ; accessed October 2, 2009.

56. Abraído-Lanza AF, Chao MT, Flórez KR. Do healthy behaviors decline with greater acculturation? Implications for the Latino mortality paradox. Soc Sci Med. 2005; 6:1243-55. 